\title{
MULTICULTURALISMO E EDUCAÇÃO
}

BASTOS, Manoel de Jesus ${ }^{1}$

BASTOS, Manoel de Jesus. Multiculturalismo e Educação. Revista Científica Multidisciplinar Núcleo do Conhecimento. Ano 02, Ed. 01, Vol. 14, pp. 110-118 Janeiro de 2017 ISSN:2448-0959

\section{RESUMO}

Alguns acontecimentos trágicos e dolorosos que hibridizaram a história brasileira, tornaram-se legivelmente percebíveis e as culturas adquiridas de outros povos, inacabáveis. A história brasileira, marcada pela eliminação de muitos que aqui tentaram chegar, mas também com a herança de culturas adquiridas dos que conseguiram chegaram, contribui ricamente, com os seus conhecimentos que ficaram registrados para outras gerações. Admite-se que essa hibridização de culturas, esse patamar de conhecimentos, etnias e costumes enraizadas no povo brasileiro, deve-se aos muitos povos que migraram para cá e que, mesmo tendo seus conhecimentos ignorados, demonstraram resistência, deixando um respaldo bastante positivo nas páginas da história brasileira.

Palavras-Chave: Culturalismo, Hibridização, Educação, Formação.

\section{INTRODUÇÃO}

As relações existentes entre educação e cultura vem provocando a necessidade de reflexões a respeito do multiculturalismo em nível global. Apesar do Brasil apresentar uma configuração própria e característica do seu povo, como população miscigênica, a hibridização das culturas não é levada em consideração como deveria. Trata-se de

\footnotetext{
${ }^{1}$ Formado em Normal Superior pela UESPI (Universidade Estadual do Piauí), Pósgraduado em Supervisão Escolar pela Faculdade de Teologia Hokemãh - Fateh e Mestrando em Educação pela Anne Sullivan University.
} 
um país construído, desde 1530, época da colonização, com uma base multicultural bastante consistente.

Os registros trágicos e dolorosos que teceram a história brasileira, são inapagáveis e as culturas adquiridas de outros povos, inacabáveis. A história brasileira pode até está marcada pela eliminação de muitos que aqui chegaram, mas as suas culturas ficaram registradas para outras gerações. Admite-se que essa hibridização de culturas, esse patamar de conhecimentos, etnias e costumes enraizadas no povo brasileiro, deve-se aos muitos povos que migraram para cá e que, mesmo mascarados, demonstraram resistência, firmando suas identidades e lutando por seus direitos de cidadania.

O multiculturalismo tem passado despercebido, frente as sociedades, no entanto, as suas marcas vem deixando um respaldo bastante positivo nas páginas da história brasileira. Por se tratar de um país cujo povo, é acentuadamente, miscigênico, o Brasil deve admitir o reconhecimento da grandeza dessa fusão de conhecimentos adquirida à custa de gotículas de suor, ao longo dos séculos. É impossível negar que em cada indivíduo, sobretudo brasileiro, haja um pouquinho de conhecimento provindo dos povos que constituíram o nosso país.

Numa sociedade altamente multicultural a igualdade de oportunidades deixa de existir integralmente para todos, ficando à sua margem os taxados de homossexuais, negros, índios e pessoas de determinadas áreas ou regiões, cujos níveis de escolarização é considerado baixo. Nessas circunstâncias, o usufruto desses direitos fica atrelado, geralmente, aos considerados brancos e de classe média ou alta. Há, portanto, a necessidade de uma política que favoreça a integralidade de todos em uma mesma sociedade, incorporando, de certa forma, o multiculturalismo e dando ênfase ao reconhecimento das diferenças.

Cada cultura possui suas origens históricas e que devem ser respeitadas. O seu condicionamento depende de cada indivíduo que, ao compreender que não existe culturas puras hibridiza os seus conhecimentos. A intensidade dos processos de 
hibridização cultural são intensos e dinâmicos. São essas dinâmicas que favorecem o aperfeiçoamento do multiculturalismo entre as sociedades.

\section{MULTICULTURALISMO E EDUCAÇÃO}

O multiculturalismo originou-se nos Estados Unidos, por volta do século XIX, cujo objetivo principal era o combate à discriminação racial, inclusive do negro, no país, com a organização de lutas pelos seus direitos civis. Encadeado por professores e doutores afro-americanos, que trouxeram para suas áreas de estudos as questões sociais, culturais e políticas de interesse exclusivo dos afrodescendentes.

Entre os anos 80 e 90, o movimento multiculturalista foi aderido por algumas universidades do país, ganhando forças com as pressões populares, conquistando espaço e criando políticas públicas em todas as áreas do poder público. Todavia, na contemporaneidade, esse movimento torna-se influenciado pela globalização, levando em conta, a necessidade dos intercâmbios culturais.

Segundo Mclaren (1997 apud PANSINI e MENEZES, 2008, p 35), existe pelo menos quatro vertentes de multiculturalismo: conservador - que almeja a construção de uma cultura comum, ou seja, que negue a diversidade de culturas existentes desde o século XIX, defendendo uma cultura padrão com embasamento na branca. Nesse caso, há uma imposição do multiculturalismo que impede o reconhecimento de outras culturas; liberal por ingenuidade - menciona a permanência de uma igualdade natural entre as diversas etnias, sem no entanto, se preocupar com a ausência de oportunidades de igualdade nos grupos sociais e educacionais; liberal de esquerda - admite a diversidade cultural, possibilitando a participação de outros grupos nas discussões multiculturais; crítico - considera os anseios voltados aos movimentos multiculturais.

O multiculturalismo crítico levanta a bandeira da pluralidade de identidades culturais, a heterogeneidade como marca de cada grupo e opõe-se à padronização e uniformização definidas pelos grupos dominantes. Celebrar o direito à diferença nas relações sociais como forma de assegurar a convivência pacífica e tolerante entre os 
indivíduos caracteriza o compromisso com a democracia e a justiça social, em meios às relações de poder em que tais diferenças são construídas. (SILVA e BRADIM, 2008, p. 64).

A hibridização de culturas é um fenômeno que teve o princípio de discussões nos Estados Unidos, Portugal e Canadá, tendo o seu termo recentemente incorporado às pesquisas brasileiras, graças as influências dos estudos culturais. Apesar da sua importância, o termo multiculturalismo encontra-se ainda em construção no nosso país. É um termo bastante abrangente que engloba várias perspectivas que se contradizem.

\section{A PLURALIDADE CULTURAL NA ESCOLA}

Depois da família, a escola é o mais apropriado sistema aberto que faz parte da superestrutura social, pois dela faz parte as crianças e jovens pertencentes as classes sociais de distintos costumes, aspectos físicos e culturais. Ela atende padrões de classes consideradas superiores e os que dela não fazem parte, ou seja, ela é o espaço onde se propicia a eficácia da prevenção e atenuação dos problemas relacionados ao preconceito. A escola, através do seu Projeto Político-Pedagógico, deve apresentar ações que demonstrem a importância do multiculturalismo em uma sociedade.

As instituições de ensino estão incumbidas de disseminar meios que propiciem a diminuição do preconceito ou discriminação cultural. Não basta falar do processo escravizativo se não for levado em conta a valorização das culturas, herdadas desse povo. Os preconceitos existentes em nosso país, são marcas seculares, resquícios da colonização portuguesa e escravização dos negros e dos índios, onde absorvia-se as suas mãos de obras e fingia disfarçar os seus muitos conhecimentos.

A exclusão social é um fenômeno que começa desde a infância, na família e dentro das escolas, por não se considerar que as diferenças físicas e a diversidade de costumes e hábitos estão dentro das normalidades sociais e amparadas por uma única lei. A discriminação e o preconceito exclui as pessoas da sociedade, privando-

Disponível em: https://www.nucleodoconhecimento.com.br/educacao/multiculturalismo-e- 
as de um direito que lhes é devido, tornando-as alheias ao exercício intelectual e profissionalizante. São ações anti-humanas que desencadeiam estímulos horripilantes, subtraindo do sujeito as suas possibilidades de reconhecimento e mérito, despersonalizando-o como cidadão.

Observa-se que as discrepâncias arraigadas entre o que a escola ensina e o que os alunos precisam aprender, são bastante acentuadas, uma vez que a realidade extra escola é muito diferente, pois grande parte desses estudantes pertencem a grupos considerados inferiores e que, portanto, não apresentam nenhuma perspectiva de vida. Daí a importância do incentivo a reflexão e investigação relacionadas a hibridização de culturas entre grupos, onde haverá a construção mútua de conhecimentos.

É comum deparar-se com histórias, que reescrevem a discriminação, de que crianças negras desejam ser brancas, adotam as suas atitudes e os seus costumes, simplesmente por se sentirem excluídas da sociedade nos aspectos culturais, políticos, econômicos e sociais. Algumas pesquisas tem relatado essa demonstração, pelo fato dessas crianças virem sendo preconceituadas pelos colegas, principalmente os de classe. Elas podem até ter acesso a matrícula e sala de aula, mas o êxito na convivência social está abaixo de suas expectativas, resultando, como consequências, reprovações e na adultice, indignação e revolta.

Contudo, o que se tem observado é a necessidade de uma formação cultural direcionada a realidade de cada povo, propiciando aos educadores a uma pontaria de resgate as suas histórias e possibilidades de expansões. A reversão desse quadro nebuloso e antissocial só será possível quando escola e sociedade investirem na criação de métodos que atendam às necessidades específicas dos alunos negros, com incentivos para a busca dos níveis cultural, cognitivo e físico.

O multiculturalismo brasileiro é o resultado da miscigenação que contribuiu, grandemente, com uma vasta área de conhecimentos, com os quais enriquecemos os 
nossos, e que seria impossível aboli-los das entranhas de nossas fontes literárias. (Grifo nosso)

Sabe-se que o processo educacional é a principal e exclusiva via de acesso ao resgate da igualdade social, efetivação da cidadania e do reparo às imagens distorcidas. A escola é o núcleo de encontro e de discussão das diferenças sociais, podendo ser instrumento que possibilite a atenuação e prevenção da exclusão. Em qualquer sociedade que se faz parte, há a possibilidade de relacionamento com diferentes indivíduos. No entanto, é preciso que se compreenda que não existe ninguém melhor que ninguém, as diferenças existentes entre os indivíduos é o que os faz normais, pois elas não devem ser observadas como entraves mas como algo complementar em suas existências.

O multiculturalismo manifestado nas análises educacionais tem gerado importantes desafios nas investigações a respeito do conhecimento e oferecido leques que proporcionaram reflexões tanto nas práticas pedagógicas, quanto na formação do indivíduo como mero reconhecedor do respeito à diferença e a pluralidade cultural. $A$ solução de supostos conflitos entre culturas, devem ter origem na família e na escola, com o objetivo de atenuá-los, uma vez que ambas estão imbuídas de preparar indivíduos para viverem em sociedade, sendo necessário esse respeito e compreensão mútua entre os mesmos.

Educação e multiculturalismo são dois fenômenos indissociáveis, tendo em vista que, ao tempo em que a escola trabalha hibridizações culturais, proporciona a compreensão do padrão aceitável que um povo precisa, para a equidade social. Vários estudos voltados ao multiculturalismo tem demonstrado grande preocupação com a presença crônica do preconceito, da exclusão social e da discriminação racial, requerendo dos órgãos governamentais e das instituições de ensino, compromissos que possam minimizar os conflitos existentes entre as diferenças.

Moreira destaca que é impossível imaginar em uma educação multicultural, sem no entanto, questionar-se sobre o professor e sua formação, tendo em vista que, somente 
através dela, o professor é capaz de realizar um trabalho eficientemente voltado à conciliação dos atritos.

\section{MULTICULTURALISMO E FORMAÇÃO DOCENTE}

Algumas pesquisas realizadas tem destacado a importância da temática multicultural nos currículos das instituições educacionais, responsáveis pela formação de professores. Para Moreira (2001), a educação multicultural deve estar inserida no currículo pedagógico, em todas as instituições de ensino, inclusive nas universidades públicas ou privadas, pois este faz-se importante na vida profissional do professor.

Que professores estão sendo formados, por meio de currículos atuais, tanto na formação inicial quanto na formação continuada? Que professores deveriam ser formados? Professores sintonizados com os padrões dominantes ou professores abertos tanto à pluralidade cultural da sociedade mais ampla como a pluralidade de identidades presentes no contexto específico em que se desenvolve a prática pedagógica? Professores comprometidos com 0 arranjo social existente ou professores questionadores e críticos? Professores que aceitam o neoliberalismo como a única saída ou que se dispõem tanto a criticá-lo como a oferecer alternativas a ele? Professores capazes de uma ação pedagógica multiculturalmente orientada? (MOREIRA, 2001, p. 43)

Percebe-se que a preocupação do autor está, explicitamente, voltada a necessidade de uma postura multicultural na sociedade contemporânea, globalizante e capitalista em que se vive, mesmo com o enfrentamento de muitas dificuldades. No entanto, somente através da formação de professores é que pode se desenvolver um espaço de novas identidades, novas posturas, novos saberes e renovadas estratégias para o reconhecimento da impressibilidade do multiculturalismo. A formação do professor está necessitando de um questionamento capaz de reformular a sua prática docente, incluindo no seu currículo, a fusão de culturas, com vistas à minimização da marginalização dos grupos subalternos. 
A educação multicultural oferece ao professor o melhor desempenho em sua tarefa pedagógica, valorizando a perspectiva do aluno e possibilitando a construção de um currículo mais próximo de sua realidade, pois uma formação multiculturalmente orientada, propiciará resultados que satisfaçam as necessidades da sociedade. $\mathrm{O}$ professor deve ser reflexivo para que possa compreender a essência da realidade social, política e cultural dos seus alunos, criando possibilidades que favoreçam as transformações reais para relações igualitárias entre os indivíduos.

Todos sabem (...) que o multiculturalismo não é a terra prometida... [Entretanto] mesmo em sua forma mais cínica e pragmática, há algo no multiculturalismo que vale a pena continuar buscando (...) precisamos encontrar formas de manifestar publicamente a importância da diversidade cultural. [...] (WALLACE, 1994 apud HALL, 2003a, p. 54)

Admite-se que o professor tem a função de propiciar a intermediação entre a cultura do aluno e os conhecimentos hibridizados no âmbito do espaço escolar. Contudo, a formação multicultural auxiliará ao professor na condução do currículo pedagógico, enriquecendo na cultura do aluno e compreendendo que a sua tarefa vai além de transmitir conteúdos. Reconhecer à existência da pluralidade cultural e valorizá-la como suporte complementar de conhecimentos é o que faz enriquecer o contexto social.

Torna-se necessário que se proponha a superação do verdadeiro reconhecimento da presença de uma diversidade de culturas em nossa sociedade, instrumentalizando professores com análises que Ihes possibilitem a percepção da importância da construção de realidades ideológicas que cubram o infame racismo que vem atropelando a democracia. A formação multicultural passa a ser, portanto, objeto de reflexão que almeja a busca de ideias fortalecedoras da legitimação de culturas empreendedoras de uma gama de conhecimentos indispensáveis a uma sociedade igualitária. 
As diferenças existentes entre indivíduos sinalizam que ser diferente é pertencer a uma normalidade e devem ser levadas em consideração para a sua emancipação política, social e cultural. O multiculturalismo favorece a mudança nas relações vividas pelos indivíduos, inserindo dentro do contexto as questões como identidade, diferenças de classe, gênero e etnia, entre outros.

\section{CONSIDERAÇÕES FINAIS}

Torna-se necessária a urgência de uma educação que valorize e inclua a diversidade cultural para o efetivo convívio multicultural entre as sociedades, valorizando o diálogo, o respeito e os valores contidos em cada indivíduo. O sistema educacional deve propiciar mudanças eficazes no desenvolvimento de atitudes e concepções, com a implementação de projetos curriculares que resultem na sensibilidade essencial do multiculturalismo. Reformas pedagógicas devem acontecer com 0 intuito de transparecer aos nossos alunos a importância do respeito e da compreensão, da aceitação, do inter-relacionamento de culturas entre indivíduos.

Descarta-se a possibilidade de existir conhecimentos isolados, uma vez que ele é adquirido com base em outros conhecimentos e em outras concepções, sendo apenas aperfeiçoado. A cultura de cada grupo é apenas uma composição do conhecimento democrático de uma sociedade.

O multiculturalismo deve ser um processo presente no ensino-aprendizagem desde os primeiros anos da educação básica à de professores. Deve ser contextualizado com a impregnação de lutas que visem a mudança social, contrapondo-se ao ideário neoliberal e a globalização cultural, capitalista e econômica a que se vive hodiernamente.

Admite-se que o respeito à vida e a diversidade cultural é imprescindível ao favorecimento da construção da paz, da afetividade e acredita-se na instituição escolar como força maior na condução desse processo para a viabilização da justiça social e da plena democracia. Nessa concepção, torna-se necessário o avanço em pesquisas teóricas e práticas que possam delinear a consolidação de identidades e 
pluralidades culturais. Faz parte da reflexão sobre a educação multicultural na formação do professor o entendimento de que a linguagem e a concepção do aluno deve ser levada em conta como manifestação de sua cultura e que contribuirá, ricamente, em outras culturas.

Todavia, há uma grande carência de estudos, desde a educação básica à universidade, a respeito do multiculturalismo, redefinindo propostas que venham alicerçar a democracia do conhecimento. O Brasil é um dos países que tem elevada miscigenação e, consequentemente, maior número de concepções culturais, carecendo da sua assimilação e do seu aprimoramento.

É necessário que haja uma formação docente pluralizada, construída por concepções diversificadas e com visão que almeje a superação universalizada dos costumes, dos hábitos e do senso crítico de cada indivíduo. Essa perspectiva poderia efetivar a organização multicultural, refletindo a valorização da pluralidade de vozes, concepções e identidades que busquem na contraposição de ideias, ou na orquestração de diferenças, a igualdade social.

\section{REFERÊNCIAS}

MCLAREN, P. (1997). Multiculturalismo crítico. São Paulo. Cortez.

MENEZES, Waléria. O Preconceito Racial e suas Repercussões na Instituição Escola.

MOREIRA, Antônio Ferreira e CANDAU, Vera Maria, (2003). Educação escolar e culturas: construindo caminhos. Revista Brasileira de Educação, no 23, mai-ago.

PASSINI, Flávia, NENEVÉ, Miguel. Educação Multicultural e Formação Docente. SILVA, Maria José Albuquerque, BRANDIM, Maria Rejane Lima. Multiculturalismo e Educação: em defesa da diversidade cultural. Diversa. Ano I. 